\title{
2006-1834: BIG BLUE: A MULTIDISCIPLINARY CAPSTONE ENGINEERING DESIGN PROJECT
}

\section{James Lumpp, University of Kentucky}

James E. Lumpp, Jr. is an Associate Professor in the Department of Electrical and Computer Engineering at the University of Kentucky. He received the BSEE and MSEE degrees from the School of Electrical Engineering at Purdue University in 1988 and 1989 respectively, and the $\mathrm{Ph} . \mathrm{D}$. from the Department of Electrical and Computer Engineering at the University of Iowa in 1993. He joined the faculty at the University of Kentucky in 1993. He is a Member of IEEE, AIAA, ACM, and SWE and the Center for Advanced Networking and the Advanced Science and Technology Commercialization Center at the University of Kentucky. He has worked as a visiting scientist or intern at AT\&T Bell Labs, Rockwell International, Northrop Defense Systems Division, and Oak Ridge National Laboratory. His research interests include distributed embedded systems, safety critical systems, and high-performance distributed computing.

\section{Jamey Jacob, University of Kentucky}

Jamey D. Jacob is professor of Mechanical Engineering with funded research projects in aerospace applications from AFOSR, NASA, General Electric Aircraft Engines, Boeing, and others. His main research interests include aircraft configuration optimization, low speed aerodynamics, vortex flows, turbulence, and experimental methods, including modern measurement techniques, particularly non-intrusive global methods such as digital particle image velocimetry and quantitative flow visualization. He is the author of over 50 papers and technical reports in the areas of aerodynamics, flow control, and measurement techniques. He received his B.S. in Aerospace Engineering from the University of Oklahoma in 1990 and his M.S and Ph.D. from the University of California at Berkeley in 1992 and 1995, respectively. He was a National Research Council Summer Faculty Fellow in the Air Force Research Laboratory at WPAFB in both 2003 and 2004. He is currently an Associate Professor in Mechanical Engineering at the University of Kentucky.

\section{Suzanne Smith, University of Kentucky}

Suzanne Weaver Smith is the Donald and Gertrude Lester Professor of Mechanical Engineering at the University of Kentucky. She received BSME and MSEM degrees from Clemson University in 1978 and 1980, respectively, and a Ph.D. in Engineering Mechanics from Virginia Tech in 1988. From 1980 through 1984, she worked at Harris Corporation, primarily performing structural dynamics analysis and vibration testing of ground and space communications systems. She is an Associate Fellow of AIAA and a Member of ASME, SEM and ASEE. Her research interests include modeling, analysis and test of nonlinear structural dynamics for inflatable and other large flexible spacecraft and of cable-stayed bridges.

\section{William Smith, University of Kentucky-Lexington}

William T. Smith is an Associate Professor in the Department of Electrical and Computer Engineering at University of Kentucky. He joined the faculty in 1990. He also worked as a Senior Engineer in the RF Design Group at Harris Corp., Melbourne, Florida, from 1981 to 1984. He has a BSEE from the University of Kentucky, 1980; MSEE and PhDEE from Virginia Polytechnic and State University, 1986 and 1990, respectively. He is a member of IEEE and ARRL. 


\title{
BIG BLUE: A Multidisciplinary Capstone Engineering Design Project
}

\begin{abstract}
The BIG BLUE project at the University of Kentucky is an attempt to integrating systems engineering concepts and processes into undergraduate engineering education. NASA is addressing the anticipated shortage of aerospace engineers through workforce development projects of the National Space Grant College and Fellowship Program. BIG BLUE is a workforce development project currently in its fourth year at Kentucky funded by NASA. BIG BLUE is a comprehensive systems engineering experience for undergraduate engineers to propose, design, and implement a complex aerospace system while managing the financial and human resources. The system the students develop is a Mars aircraft and a prototype highaltitude test-bed UAV that is launched in high Earth atmosphere. In essence, students involved in BIG BLUE joined the aerospace workforce while participating in the project, which influenced their decision to choose and pursue an aerospace career. Opportunities were also available to visit and work with practicing aerospace engineers in industry and at NASA. Annual support and expenditures, student and faculty involvement in project management and aerospace workforce development results are included. With three successful flight experiments in three years, a review of BIG BLUE reveals the effort, cost and results of experiential systems engineering and aerospace workforce development.
\end{abstract}

\section{Introduction}

BIG BLUE is a high-altitude experiment developed, designed, built, conducted and evaluated primarily by undergraduate students. BIG BLUE (Baseline Inflatable-wing Glider, BalloonLaunched Unmanned Experiment) was first proposed in 2002 to NASA's Workforce Development program with the objective to involve talented engineering students in a state-ofthe-art aerospace project, with opportunities to do complex multidisciplinary research and development and to interact as peers with researchers at NASA centers and in the aerospace industry. BIG BLUE was first conceived as a demonstration of unique inflatable-wing technologies with potential application for extraterrestrial exploration. ${ }^{1-3}$ Currently, technologies are developed for BIG BLUE with additional consideration of other Unmanned Aerial Vehicle (UAV) applications. In essence, students join the aerospace workforce while participating in this project, and consequently learn about careers in aerospace engineering.

Development and execution of BIG BLUE is a complex combination of spacecraft and aircraft concepts and technologies including aeronautics, communications, power, microprocessor control, structural analysis and system testing. Consequently, it provides a comprehensive technical experience for all involved. The experience of developing a complex aerospace system of the scope of BIG BLUE is uncommon in engineering curricula, and produces graduates with technical expertise, as well as unique experience in systems engineering and with multidisciplinary teams. These students are valuable to all employers, but especially so in the aerospace industry. A number of BIG BLUE students have chosen to pursue aerospace careers when such a choice was unlikely without their involvement in the project. To date over 160 students, primarily in mechanical engineering and in electrical and computer engineering at UK, 
have participated in BIG BLUE with $12.5 \%$ entering the aerospace workforce. Additionally, Mars exploration and BIG BLUE are exciting topics that capture the imagination, providing an opportunity to initiate interest in aerospace careers through wider BIG BLUE outreach efforts to K-12 students and the general public.

The technical goal of BIG BLUE is to demonstrate the feasibility of inflatable wings for flight in the low-density atmosphere of Mars. Before developing a flight experiment, however, several questions about inflatable wing designs for low Reynolds Number flight and UV-rigidizing composite materials required resolution. Details of the analyses and wind-tunnel experiments to define the wing cross-section design and to understand the aeromechanics of inflatable wings for this flight regime were presented previously. ${ }^{4,5}$ Details of structural analyses, thermal-vacuum experiments and weight-optimization studies are also available. ${ }^{6,7}$ Related investigations regarding the flight characteristics of inflatable/rigidizable wings and of inflatable (but not rigidizing) wings and of the application of inflatable wings for wing warping and morphing have documented their stability in low-altitude flight, along with their survivability. ${ }^{8,9}$

On Earth, the analog environment for testing Mars "airplane" technologies is at an altitude of approximately 100,000 ft. Experiments to verify Mars "airplane" technologies reach this altitude via weather balloon, so designs for minimal weight and power, capabilities for long-range communications and autonomous operation are requirements. In addition to developing capabilities at UK for communications compatible with the balloon-launch organization, Edge of Space Sciences in Denver, CO, fault-tolerant architectures and related technologies were implemented. Mission control and ground station designs are presented in detail elsewhere. ${ }^{10}$

In this paper, an overview of the technical accomplishments of the BIG BLUE project is provided in the next section, along with the plan for phased development of the culminating high-altitude experiment and highlights of the three experiments to date. Descriptions of the student experiences have been presented previously, ${ }^{11,12}$ but the three-year perspective provides an opportunity for more comprehensive review of the educational and project management of a student project of this technical complexity and scope. Courses, NASA and industry interaction and support are summarized. Finally, workforce development results will be presented.

\section{The BIG BLUE Flight Experiments}

The BIG BLUE flight experiments are the focus for the student experience for aerospace workforce development. They are a series of increasingly-capable and increasingly-complex systems designed to execute the high-altitude deployment of inflatable wings and to measure their performance.

\section{Project Objectives}

The primary objective for the BIG BLUE project is to provide a comprehensive aerospace research and development experience for talented students to introduce them to, prepare them for and encourage them to pursue a career in the aerospace industry. BIG BLUE was originally conceived in July 2002. A team of 20 to 25 students was envisioned to design, build, ground-test and conduct the experiment during the Spring 2003 academic term. 


\section{Overview of Phased Development}

Each of the three BIG BLUE flight experiments to date has increased the system capabilities toward the final flight experiment that will complete all stages of the original concept. BIG BLUE I experiment objectives were to demonstrate the feasibility of inflatable-rigidizable wing technology by completing the first two stages of the overall concept. After deployment, the cured, inflated wings descended under parachute for recovery and post-flight evaluation. In Fall 2003, post-flight evaluation also included low-altitude flight testing to demonstrate flight worthiness and to determine flight characteristics.

The experiment concept for BIG BLUE II is presented in Figure 1. After completing the first two stages as before, the third stage of the experiment is modified. Here, the test article descends under parachute to low altitude where the aircraft separates from the descending balloon payload string for a short autonomous flight before deploying an onboard parachute for landing.

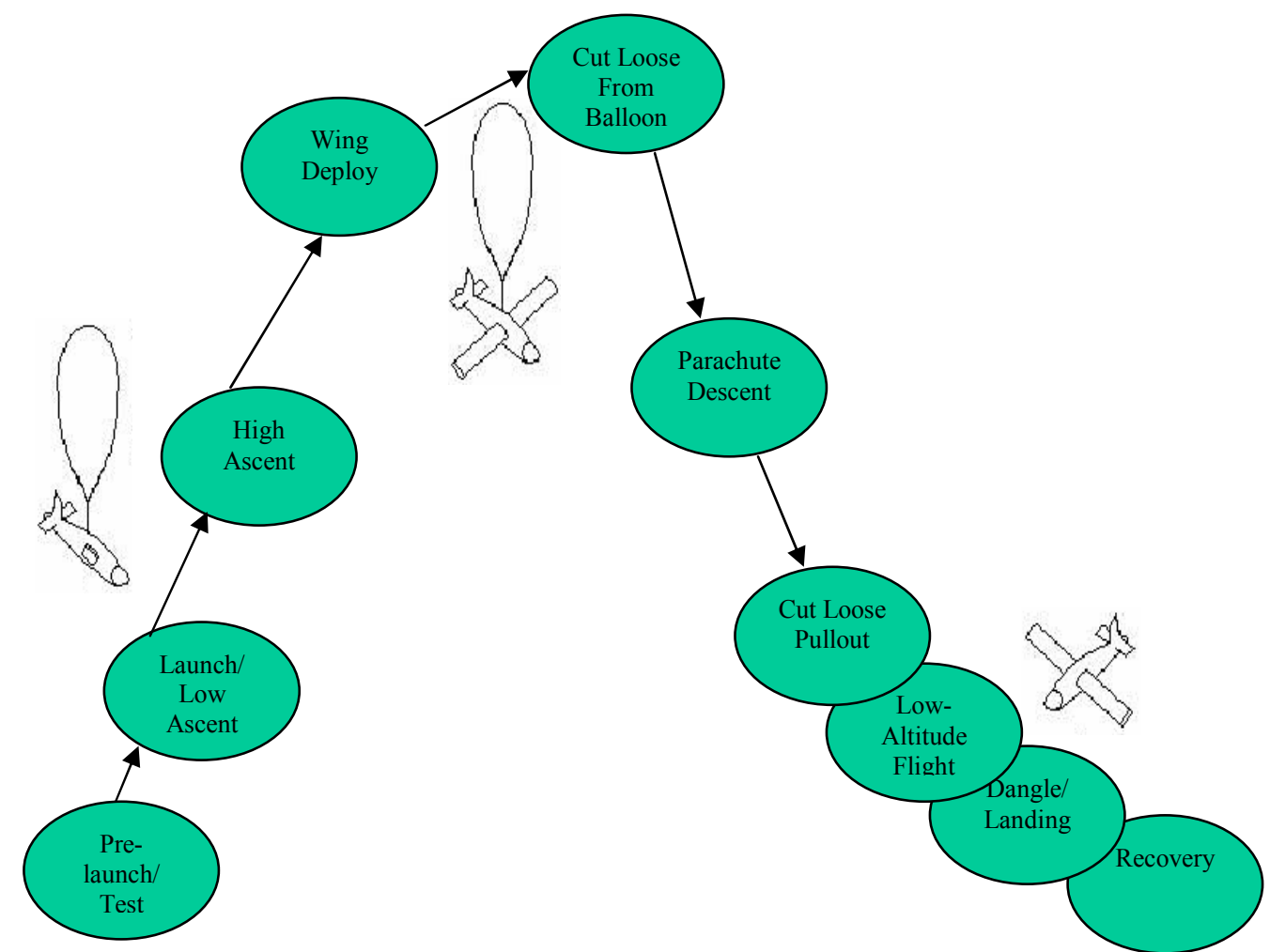

Figure 1. Flight experiment concept for BIG BLUE II including low-altitude flight in third stage.

For BIG BLUE 3, inflatable, but not rigidizable, wings were to be evaluated. The flight experiment concept repeated that of BIG BLUE I, completing the first two stages of the overall concept before decent under parachute for recovery. However, to advance the autonomous flight capability for later balloon-launched experiments, an additional objective was competing in the Association of Unmanned Vehicle Systems International (AUVSI) 2005 Student UAV Competition on July 2, 2005. This competition requires an autonomously flying vehicle with onboard cameras for identification of targets on the ground. An aircraft was also designed for the 
competition and for later integration with inflatable wings toward the culminating Mars airplane experiment.

\section{Highlights of Completed Flight Experiments: BIG BLUE I, BIG BLUE II and BIG BLUE 3}

The balloon flight payload for each of the BIG BLUE flight experiments included several components in addition to the BIG BLUE test article. Figure 2 presents a labeled illustration of the balloon flight payload string, along with images of the ascending balloons and payloads from the three flight experiments to date.

BIG BLUE I was the development of an experimental UV-curable composite wing design, and culminated in - for the first time anywhere - a flight experiment demonstrating the successful deployment and cure of inflatable/rigidizable wings. On May 3, 2003, near Ft Collins, Colorado, the inflatable wings were deployed and hardened at an altitude of 55,000 ft. The experiment reached a peak altitude of $89,603 \mathrm{ft}$ before returning to the ground under a parachute. BIG BLUE I included successful tests of other student-designed prototype component systems including the communications systems, sensors, still camera and microprocessor control managing the deployment, sensors, communications, and data storage. Onboard GPS was an important requirement for tracking. When the primary GPS provided with the launching balloon failed during the flight, a UK student-written telemetry interface system provided UK ground station operators with location coordinates from the BIG BLUE GPS that were used to report the experiment location to the FAA.
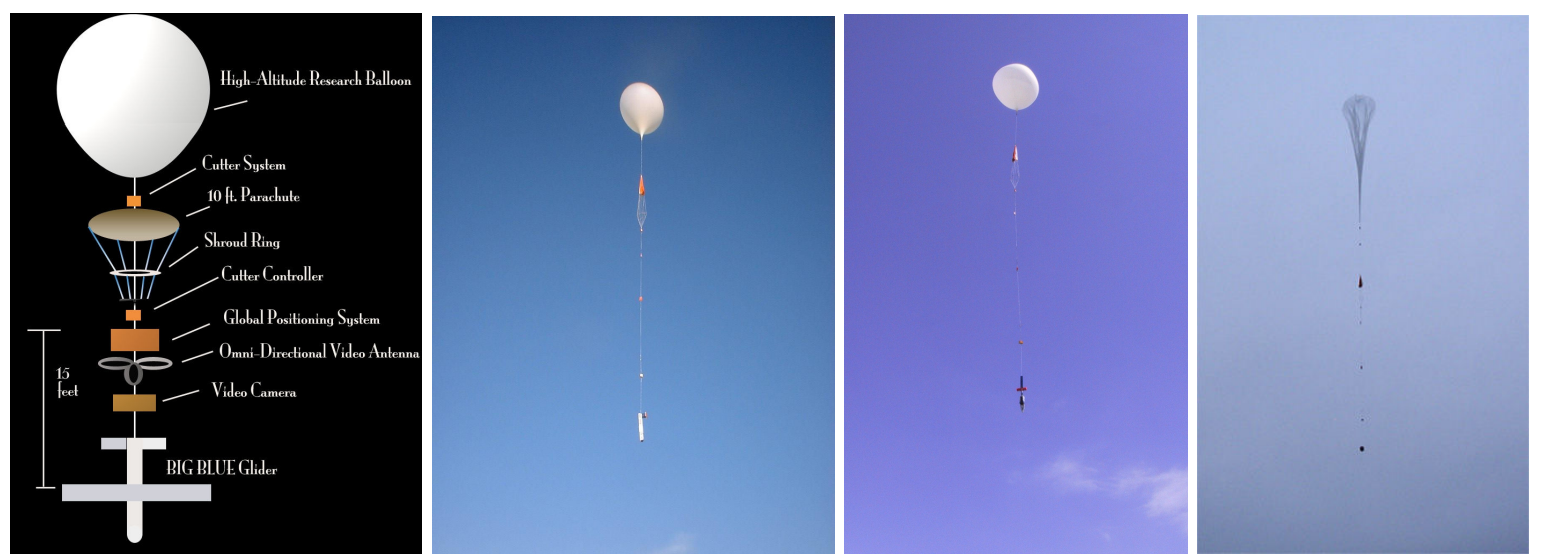

Figure 2. (left to right) Flight Payload Illustration; Launches on May 3, 2003, May 1, 2004 and April 30, 2005.

The onboard camera recorded images of the BIG BLUE I wings after deployment (Figure 3). In the summer of 2003, an extensive post-flight testing and calibration effort was conducted, including post-flight analysis of the flight data and telemetry.

In BIG BLUE II, a second generation UV-curable composite wing design was developed to optimize weight and composite strength. BIG BLUE II also included development of a composite fuselage, parachute system, power monitoring system, custom autopilot and secondgeneration communications and mission control systems. Unlike BIG BLUE I, the vehicle was flight-ready having undergone many hours of low-altitude flight-testing before launch. BIG 
BLUE II was launched successfully on May 1, 2004; the wings were deployed and cured to a symmetric flying shape (Figure 4). Due to FAA regulations for UAV testing, autonomous flight was only permitted below an altitude of $1,500-3,000 \mathrm{ft}$ above ground level and with visual contact of the vehicle. Thus, the vehicle descended from the peak altitude under parachute. However, for BIG BLUE II, a premature rupture of the ascent-system balloon resulted in descent away from the ground spotters and so returned to ground via the parachute. BIG BLUE II included successful demonstration of student-designed prototype component systems including the inflation system, multi-processor mission control providing flight control, mission management and deployment sequence triggering. In the summer of 2004, work continued on flight testing of the BIG BLUE II wings. Post flight analysis of the flight data and telemetry was also conducted.

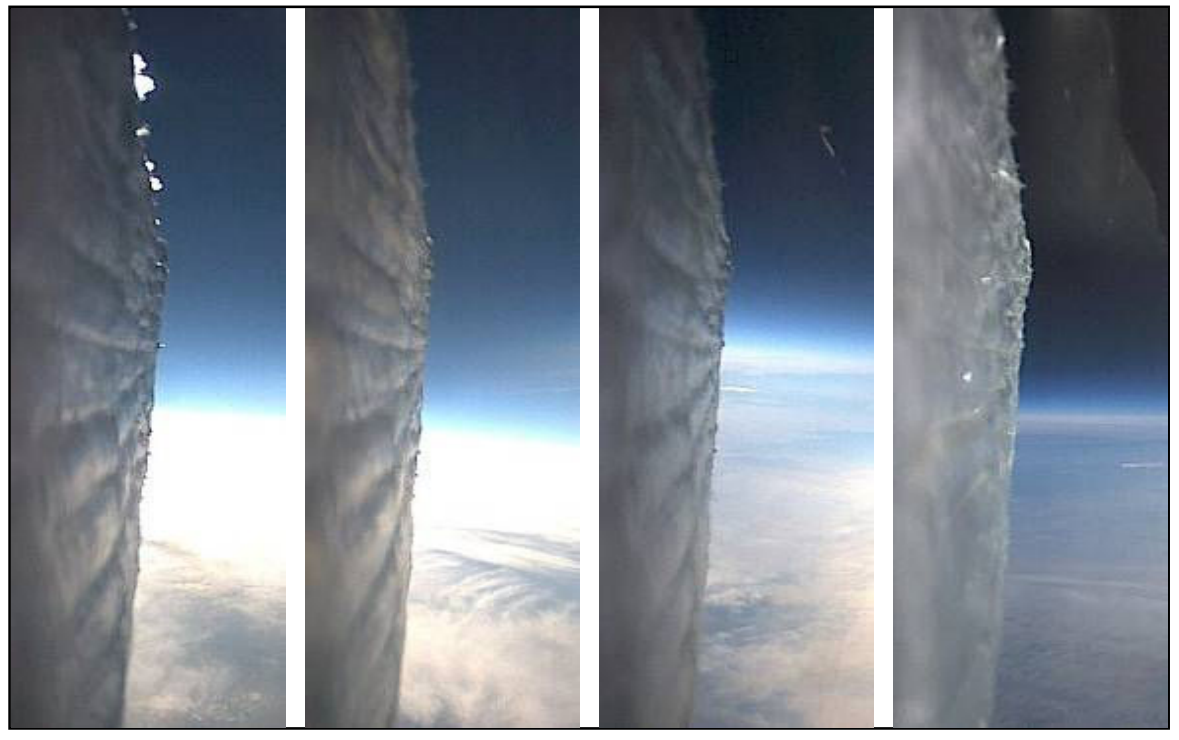

Figure 3. BIG BLUE I images of deployed wing as it cured on ascent from 55,000 ft to $89,000 \mathrm{ft}$.

For BIG BLUE 3, the change to focus on inflatable wings required a redesign of the onboard inflation system. Inflation pressures between 10 and 20 psi were required to maintain wing stiffness characteristics for flight. BIG BLUE 3 was launched successfully on April 30, 2005; the wings were deployed at approximately $96,000 \mathrm{ft}$ prior to balloon burst at approximately 98,000 $\mathrm{ft}$. Images from the onboard still camera are seen in Figure 5 prior to deployment and after deployment. The inflation system maintained sufficient pressure throughout the descent, including passage through minimum temperatures of $-40^{\circ} \mathrm{F}$. BIG BLUE 3 included successful demonstration of student-designed prototype component systems including the new paintballbased inflation system, onboard amateur radio band television (ATV) and of the Vectran inflatable wings. Post flight analysis of the flight data and telemetry was completed. 


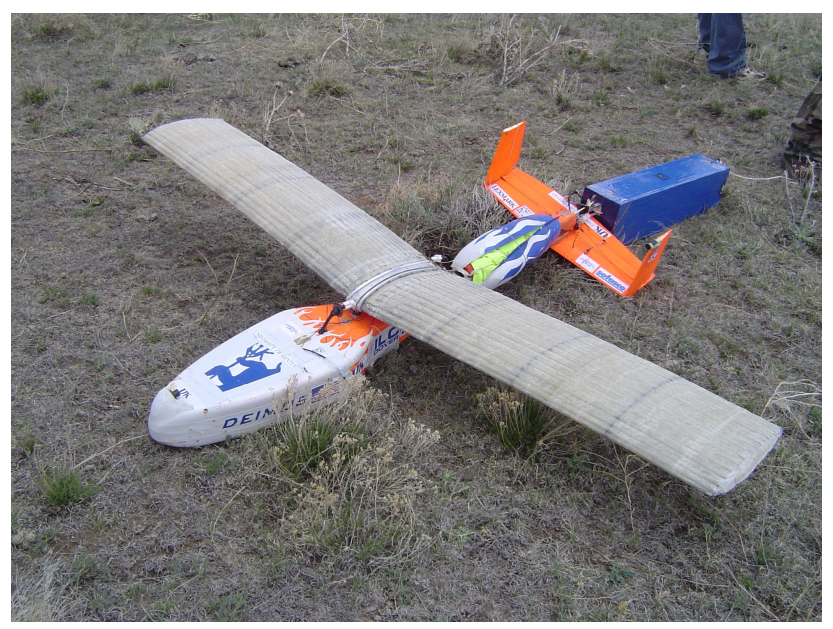

Figure 4. BIG BLUE II aircraft and attached inflation system at the recovery site.

Almost immediately after the balloon-launched experiment (and graduation), high-intensity efforts began for the UAV competition. Throughout the Spring 2005 term, a new aircraft was developed, along with capabilities for communication with a purchased autopilot, a new ground station and image processing for target recognition. Maiden flights of two competition aircraft occurred in May 2005, and flight testing continued throughout June 2005. On July 2, 2005, the UK BIG BLUE 3 team successfully completed all requirements of the UAV competition mission and placed $6^{\text {th }}$ overall of 13 teams.
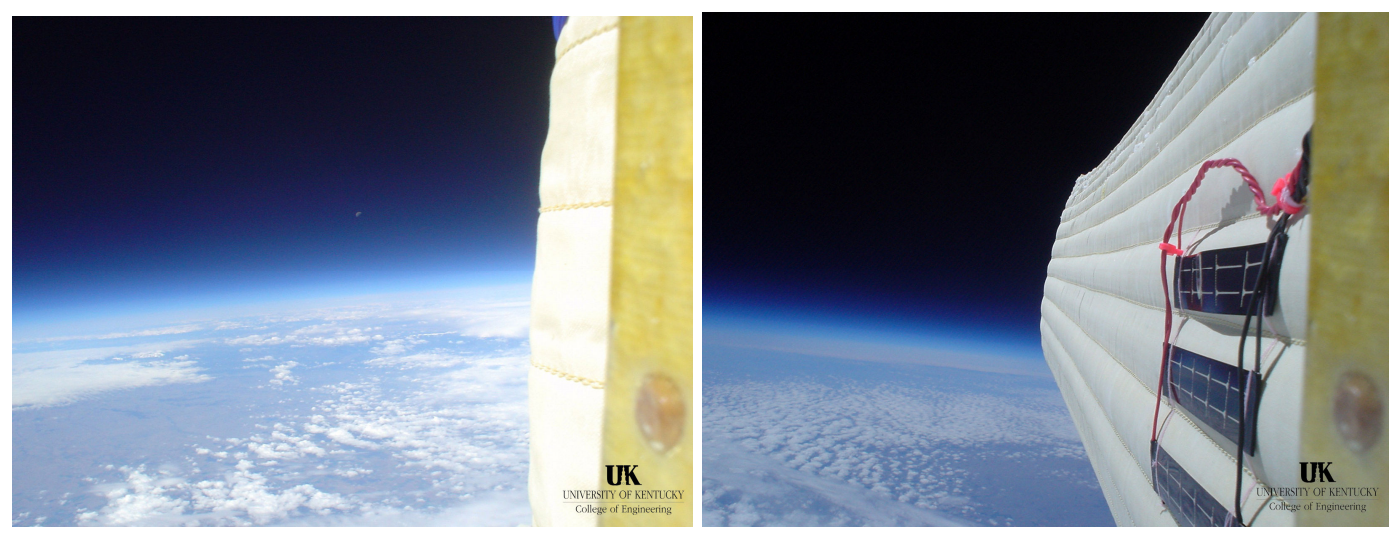

Figure 5. Flight images from BIG BLUE 3 including pre-inflation (left) and post-inflation (right). Maximum altitude was approximately 98,000 ft.

\section{Project Organization and Management}

For the first three years of the BIG BLUE project, the majority of the effort took place during the Spring term, culminating in a balloon-launched flight experiment in Denver, CO, the weekend just before final exams and graduation. This schedule was not ideal, but was determined by the availability of funding - typically in February - and by the curricula of the programs involved. Capstone Senior Design courses were one-term courses, so the primary effort was concentrated 
during the Spring term with very small efforts (maybe 5-6 students) during the Fall terms in between.

\section{Courses}

Although planning for the annual project was completed in part in the fall, the projects were conducted by students enrolled in capstone design courses in Mechanical Engineering (ME) and in Electrical and Computer Engineering (ECE) primarily during the 4.5 months of the Spring term each year. Coursework included technical subjects required for the project including spiral design process and design optimization. Students in the communications course all became licensed amateur radio operators. Several courses were developed and taught in support of this program

In addition to required and technical elective coursework, BIG BLUE students were offered the opportunity to attend a short course on Aerospace Systems Engineering, taught by Dr. Frank Bourne, an aerospace communications systems engineering consultant with over 20 years of experience. This short course was offered before classes started for the term or on a Saturday, with students spending time developing the experiment mission plan as an exercise at the end of the course. BIG BLUE students also participated in "Learn-to-Fly" workshops and conducted workshops for pre-engineering high school students in the summer.

\section{NASA and Industry Interaction}

One of the keys to success of the BIG BLUE program has been student interaction with experts. Foremost among the many examples during the three years of the BIG BLUE project is the partnership with ILC Dover, Inc., maker of NASA's spacesuits and the Mars lander airbags. ILC Dover worked with the BIG BLUE students each year, including helping to define the initial experiment concept in Fall 2002. The ILC Dover engineers provided insight and design advice based on their prior development efforts in inflated wings and in inflatable/rigidizable spacecraft. For BIG BLUE I and II, unique state-of-the-art rigidizable epoxies were provided to students studying curing characteristics; time and materials required for fabrication of the test articles and spares were also provided under a subcontract. ILC Dover also contributed engineering time for the development of the inflatable/rigidizable (IR) wings. For BIG BLUE 3, surplus Vectran material from the Mars lander airbags was used to construct the inflatable wings under contract.

Each year, ILC Dover contributed engineering time and valuable advice during the critical design reviews. Student designs were evaluated by ILC Dover engineers and project managers during a formal critical design review held at ILC Dover (e.g., BIG BLUE II Design Review, Figure 6). Students presented their proposed designs and received feedback from the experienced engineers. Additional discussions during breaks (Figure 8) showed students interacting as peers with ILC engineers. 

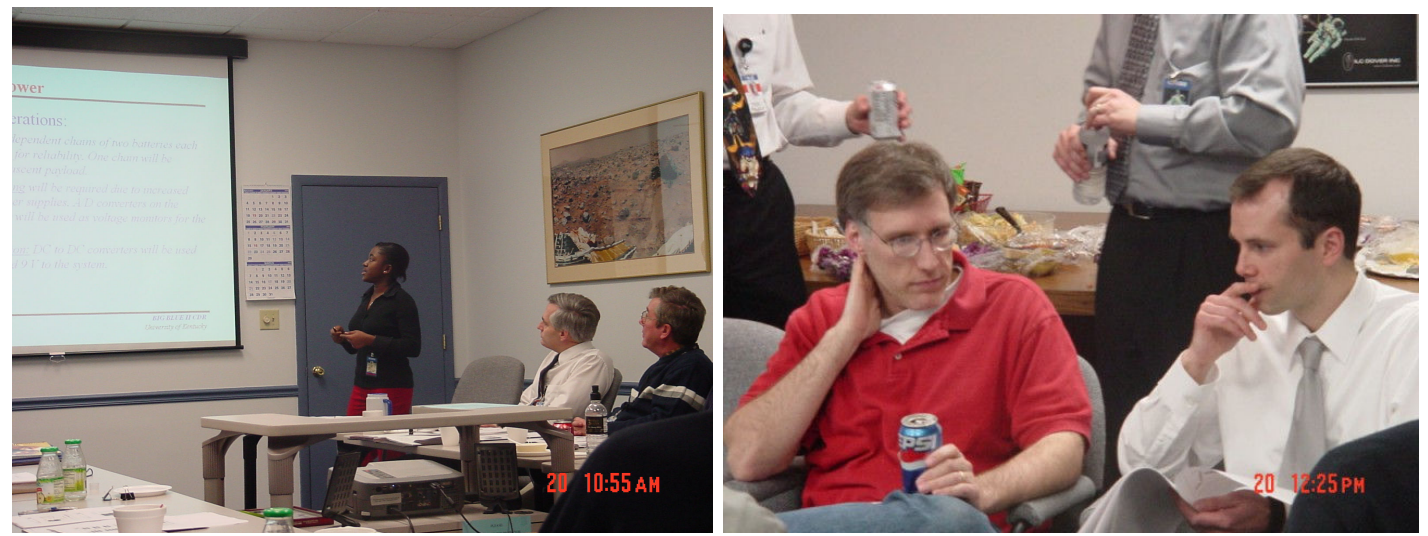

Figure 6. Critical design review presentation for the Director of Engineering, Mars Lander Airbag Project Managers and other engineers at ILC Dover, Inc. (left) and a BIG BLUE II student in conversation with an engineer from ILC Dover about the power system (right).

Additionally, students made trips to three NASA facilities (Figure 7) to present the BIG BLUE project and to discuss related technologies. At NASA Ames, the focus was on exploring Mars, but including fuselage design and integration for high-altitude testing. At NASA Langley, BIG BLUE I students and faculty learned about large inflated spacecraft and optical measurement techniques. At the Wallops Island Flight Facility, BIG BLUE I students learned about highaltitude ballooning.
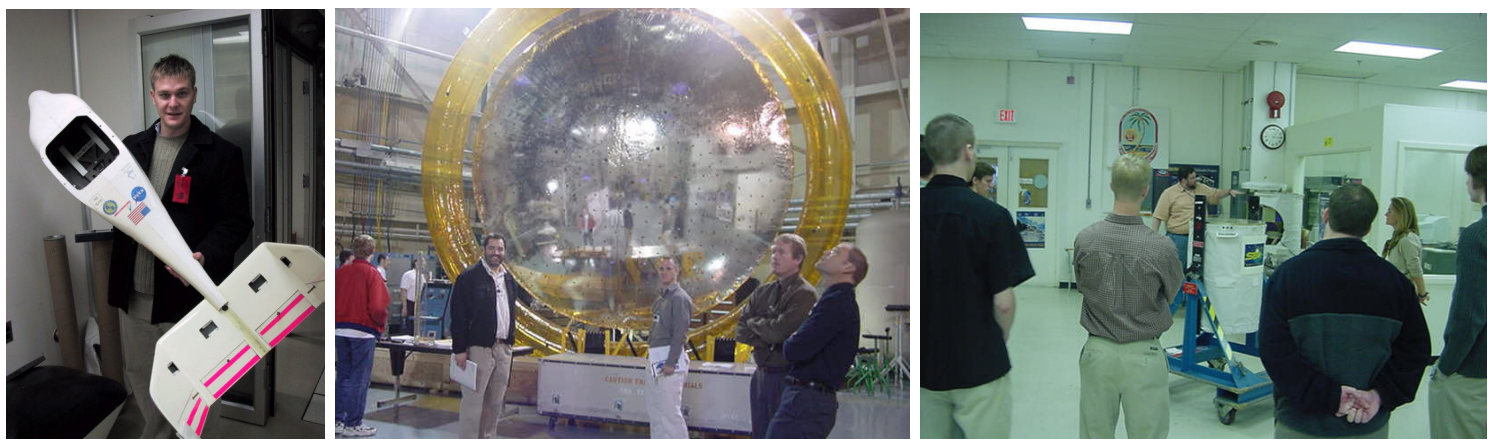

Figure 7. (left to right) A student holds the "Kitty Hawk" Mars Airplane fuselage (currently on loan to UK) at NASA Ames, February 2004; on tour of the NASA Langley Research Center in Hampton, VA, January 2003; students learned about NASA's high-altitude balloons at the Wallops Island Flight Facility, January 2003.

For BIG BLUE 3, including autonomous flight capabilities development, students visited two UAV manufacturers: Aurora Flight Sciences in Clarksburg, WV and Griffon Aerospace in Huntsville, AL.

\section{Project Management}

A shared laboratory was developed for BIG BLUE to facilitate communication among the many system teams. A shared drive for file sharing also enabled communication among the teams. Project support totaled approximately $\$ 120 \mathrm{k}$ each year with a base grant of $\$ 80 \mathrm{k}$ from the 
Kentucky Space Grant consortium. Of this base grant, the subcontract for the wing fabrication was $\$ 30 \mathrm{k}$ each year. Even with this large subcontract each year, the majority of the support was used for students, including travel, team leader stipends, and graduate student support for key technology developments. Figure 8 presents charts of the support and of the expenditures for a typical year, BIG BLUE II.
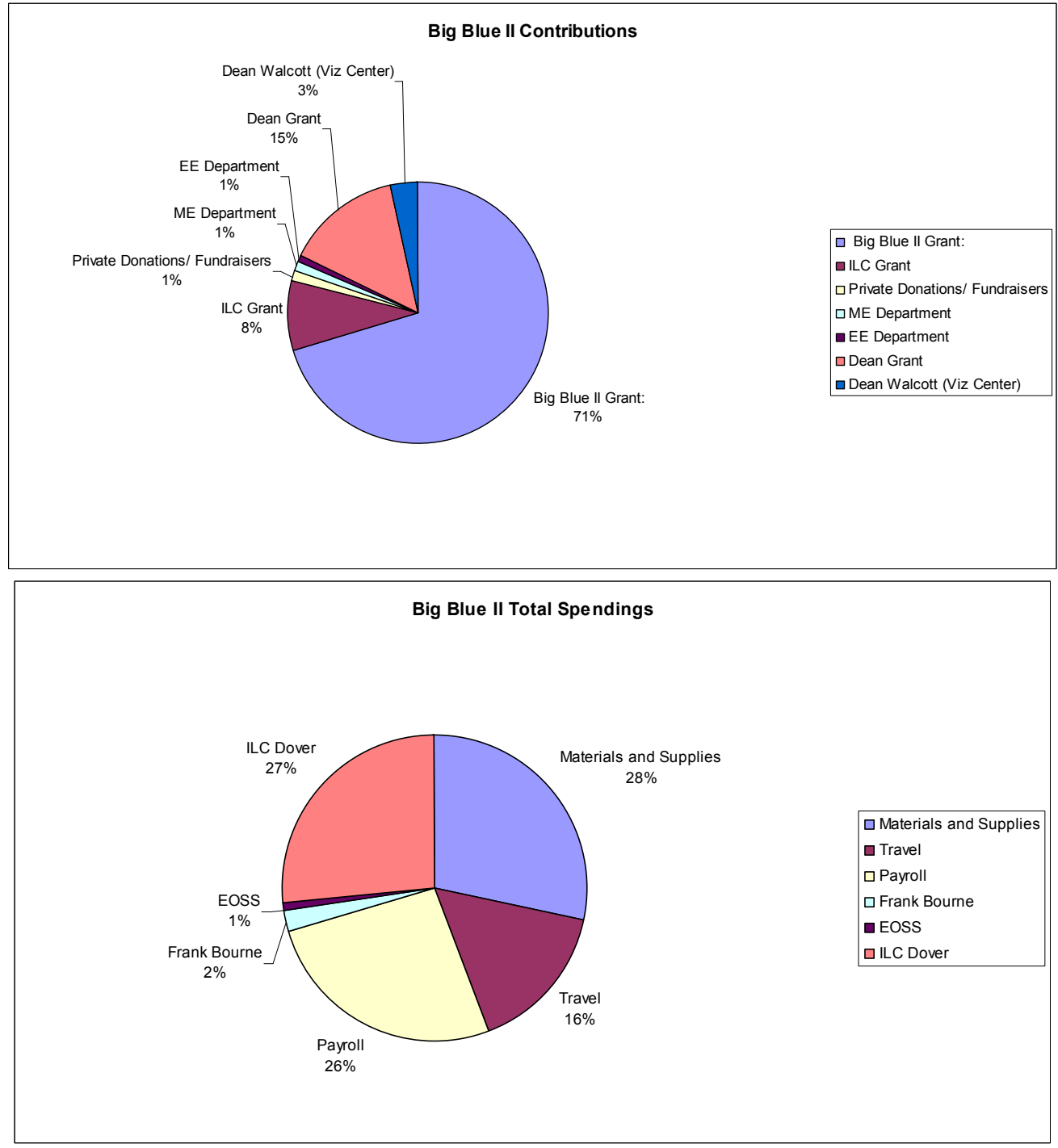

Figure 8. BIG BLUE II support and expenditures, typical for each year.

\section{Workforce Development Results}

Over the three years of the BIG BLUE program at the University of Kentucky, more than 160 students have participated as illustrated in Figure 9. Participants are primarily undergraduate students in ME and ECE, although a few students majoring in Computer Science and Biosystems and Agricultural Engineering have also been involved. One student majoring in business leads the effort to build a permanent wind-tunnel display for the Kentucky Aviation Museum, part of the outreach effort. Four students from Asbury college majoring in Media Communications filmed and edited short documentaries of the BIG BLUE student experience. Twenty students who participated in BIG BLUE are now working for aerospace industry or attending graduate 
school in aerospace programs or researching aerospace topics. BIG BLUE students are currently working for GE Aircraft Engines, Boeing, ILC Dover, SAIC, and L3, among others. BIG BLUE students are pursuing graduate degrees in aerospace at the University of Maryland and the University of Kentucky. One BIG BLUE alumnus is currently in training to be a pilot for the US Air Force.

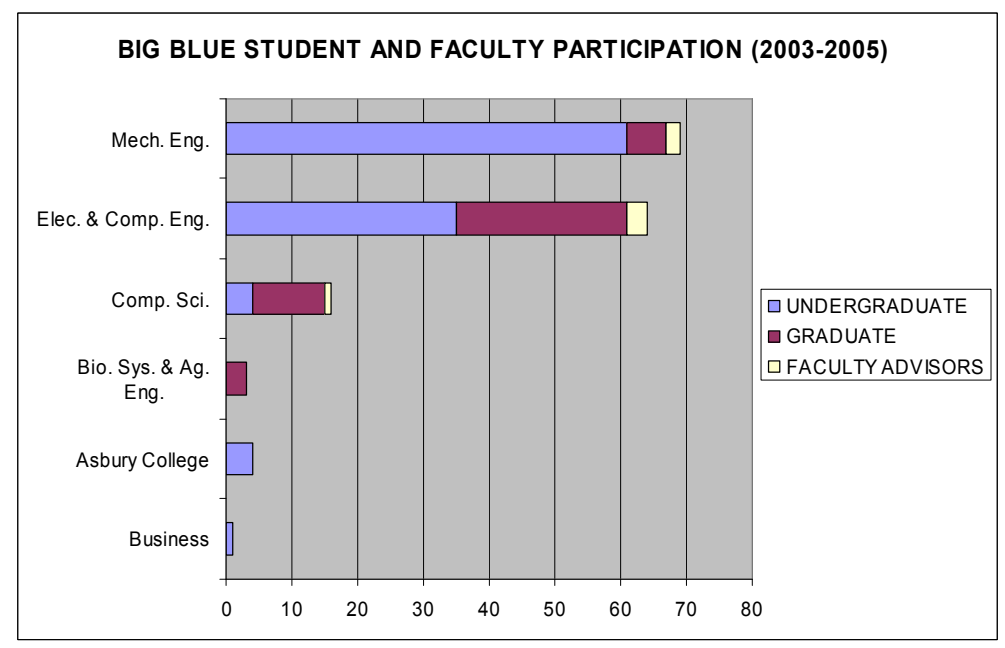

Figure 9. Summary of BIG BLUE student and faculty participation.

\section{References}

1. Smith, S.C., et. al., "The Design of the Canyon Flyer, an Airplane for Mars Exploration," AIAA Paper 20000514, AIAA Aerospace Sciences Meeting, Reno NV, January 2000.

2. Landis, G.A., A. Colozza, and C.M. LaMarre, "Atmospheric Flight on Venus," AIAA Paper 2002-0819, AIAA Aerospace Sciences Meeting, Reno, NV, January 2002.

3. http://marsairplane.larc.nasa.gov/, April 13, 2005.

4. Usui, M., "Aeromechanics of a Low Reynolds Number Inflatable Wing," Masters Thesis, University of Kentucky, 2004.

5. Simpson, A.D., Usui, M., Smith, S.W., Jacob, J.D., "Aeromechanics of Inflatable Wings," AIAA Paper 20042233, AIAA 34 ${ }^{\text {th }}$ Fluid Dynamics Conference, Portland, OR, June 2004.

6. Kearns, J.D., M. Usui, S.W. Smith, S.E. Scarborough, T.R. Smith and D. Cadogan, "Development of UVCurable Inflatable Wings for Low-Density Flight Applications," AIAA Paper 2004-1503, AIAA Gossamer Spacecraft Forum, Palm Springs, CA, April 2004.

7. Usui, M., J.D. Jacob and S.W. Smith, S. Scarborough and D. Cadogan, "Second Generation Inflatable/Rigidizable Wings for Low-Density Flight," AIAA-2005-1883, AIAA Gossamer Spacecraft Forum, Austin, TX, April 2005.

8. Simpson, A., et.al., "Flying on Air: UAV Flight Testing with Inflatable Wing Technology," AIAA 20046570, AIAA Unmanned Unlimited Conference, Chicago, IL, September 2004.

9. Simpson, A., Jacob, J.D., and Smith, S., "Morphing of Inflatable Wings." AIAA 2005-2110, AIAA SDM Adaptive Structures Conference, Austin, TX, April, 2005.

10. Rawashdeh, O., Lumpp, J.E., et. al., "Design of a Low-cost Avionics, Mission Control and Ground Communication System for a High-Altitude UAV," IEEE Aerospace Conference, Big Sky, MT, March 2005.

11. Simpson A., O. Rawashdeh, J.D. Jacob, J.E. Lumpp, S.W. Smith and W.T. Smith, "BIG BLUE II: Mars Aircraft Prototype with Inflatable-Rigidizable Wings" AIAA-2005-0813, AIAA Aerospace Sciences Meeting, Reno, NV, Jan 10-13, 2005.

12. Simpson, A.D., et. al., "BIG BLUE: A High-Altitude UAV Demonstrator of Mars Airplane Technology," IEEE Aerospace Conference, Big Sky, MT, March 6-10, 2005. 